\title{
Prevalence of tuberculosis among southern Zambian cattle and isolation of Mycobacterium bovis in raw milk obtained from tuberculin positive cows
}

\author{
Girja S. Pandey ${ }^{1}$, Bernard M. Hang'ombe ${ }^{1}$, Festus Mushabati ${ }^{2}$ and Andrew Kataba ${ }^{1}$ \\ 1. School of Veterinary Medicine, University of Zambia, PO Box 32379, Lusaka, Zambia \\ 2. School of Medicine, Copperbelt University, PO Box 71191, Ndola, Zambia \\ Corresponding author: Girja S. Pandey, email: pandeygs@gmail.com \\ Received: 24-09-2013, Revised: 04-11-2013, Accepted: 06-11-2013, Published online: 18-12-2013
}

doi: 10.14202/vetworld.2013.986-991 How to cite this article: Pandey GS, Hang'ombe BM, Mushabati F and Kataba A (2013) Prevalence of tuberculosis among southern Zambian cattle and isolation of Mycobacterium bovis in raw milk obtained from tuberculin positive cows, Veterinary World 6(12): 986-991.

\begin{abstract}
Aim: To determine the prevalence of tuberculosis among traditional milking cows in southern Zambia and isolation of Mycobacterium spp from the tuberculin positive cow's milk.

Materials and Methods: A total of 1,025 cows originating from traditional cattle sector, in Mapepe, Magoye, Monze, Batoka, GART- Batoka, Kalomo areas of Zambia, supplying major quantity of milk to milk processors, were tested for bovine tuberculosis using single comparative intra-dermal tuberculin test during 2011 and 2012. Milk samples obtained from 16 bovine tuberculin reactor cows were cultured for isolation of Mycobacterium spp and those showing growth of Mycobacterium spp. were identified through biochemical tests of the culture. Further confirmation and species differentiation of the Mycobacterium spp. isolates was done using the loop-mediated isothermal amplification system and multiplexpolymerase chain reaction
\end{abstract}

Results: $27(2.6 \%)$ of the cows tested were found tuberculin reactors, 9 cows $(0.87 \%)$ gave inconclusive reaction and 989 $(96.48 \%)$ were non-reactors. Three milk samples (18.7\%) out of the 16 tuberculin reactor cow's milk when cultured and upon molecular analysis, were found positive for presence of $M$. bovis indicating these positive cows were shedding $M$. bovis in their milk.

Conclusion: The isolation of $M$. bovis in freshly drawn milk from the tuberculin positive reactor cows is being reported for the first time in Zambia. Bovine tuberculosis is an animal and human health risk in the traditional dairy herds supplying milk to the Zambian population especially in the informal market and needs attention of the public health and veterinary authorities.

Keywords: cattle, isolation, Mycobacterium bovis, tuberculin reactors, raw milk, Zambia

\section{I ntroduction}

Zoonotic tuberculosis is a chronic, infectious, contagious, debilitating disease caused by Mycobacterium bovis, that has become a resurgent problem in animals and humans in a number of developing countries. Tuberculosis has been reported to be endemic in both domestic and wild animals in Zambia [1,2, 3]. Bovine tuberculosis (BTB) a major zoonotic disease with worldwide distribution especially in developing countries where disease is endemic, is an important for both economic and public health reasons [4]. In cattle, the disease is mainly caused by the bacteria $M$. bovis. Mycobacterium tuberculosis in cattle accounts for a small proportion of usually sub-clinical cases [5]. Bovine tuberculosis used to be a serious zoonosis and represented a tremendous public health problem in developed countries mainly through consumption of contaminated unpasteurized milk. However after the disease was controlled in cattle through designed test and slaughter schemes together with milk pasteurization and public awareness and education, incidence

Copyright: The authors. This article is an open access article licensed under the terms of the Creative Commons Attribution License (http://creativecommons.org/licenses/by/2.0) which permits unrestricted use, distribution and reproduction in any medium, provided the work is properly cited. has drastically reduced and in some cases the transmission of BTB to humans is controlled [6]. In developing countries particularly in low income group, bovine tuberculosis is still prevalent and is responsible for significant economical loss in animal production through reduced milk yields and low reproductive performance [7]. The global prevalence of human tuberculosis due to $M$. bovis has been estimated at $3.1 \%$ of all human tuberculosis cases [8]. In countries where majority of poor rural pastoral communities depend on cattle for their livelihood, BTB is reported to be a constant threat due to lack of pasteurization of milk and tradition and culture of consuming raw milk and its other preparations. In most African countries, consumption of unpasteurized milk is a regular practice [9]. Exact data on the prevalence of human disease due to $M$. bovis in Zambia and other developing countries is absent or limited owing to technical problems posed by identification of this species such as trained personnel and laboratory facilities. This lack of information on BTB in many African countries including Zambia has lead to reduced attention to this infectious agent $(M$. bovis) in terms of prioritizing resources devoted to its research capacity, control of animal diseases and public education. Mwachalimba et al [10] in his recent 
publication from Zambia reported that using test and slaughter of livestock and promotion of milk pasteurization will reduce the zoonotic transmission of BTB and reduce the cost of treatment among humans. Bovine tuberculosis is known to be a major cause of human extra pulmonary tuberculosis and is of particular concern in developing countries where milk is often not pasteurized or boiled before use. The reason for this is that the major mode of exposure to M. bovis infection in humans is through drinking of raw milk, and $M$. bovis in humans mainly manifests as an extra-pulmonary form [11]. In Zambia, reports indicate that $M$. bovis infections could be a problem not only in cattle but in humans too [12]. Out of the estimated 253 million litres of milk produced annually in Zambia, only about 44 million litres goes through formal processing while the remaining milk is consumed as raw [13], thus exposing the public to health risks. The trend is worrying, when Zambia has prevalence rate of $14 \%$ of HIV, a synergist of tuberculosis while estimated incidence of all forms of human tuberculosis is 707/100,000 [14]. The prevalence of BTB in Zambia among traditional cattle, in selected cattle rearing areas has been reported to be $6.8 \%$ by Munyeme et al [2], 7.4 \% by Cook et al [12], $7.8 \%$ by Sitima et al [15], $6.3 \%$ by Muma et al [16], and in all these areas people consume mostly raw milk or sour milk made from raw milk without boiling.

Zambian human population also carries the tuberculosis burden in Africa. The emergence of drug resistant strains of Mycobacterium spp., the rise and synergism of HIV/AIDS infection with tuberculosis, poverty and neglect of bovine tuberculosis control programs have contributed immensely to the resurgence of TB [16]. While M. bovis is a major cause of pulmonary tuberculosis in cattle, it is also the primary cause of extra-pulmonary tuberculosis in humans where milk is consumed fresh and unpasteurized [911]. The clinical signs of this infection in humans are hardly differentiated from those caused by the classical human type and are often difficult to assess clinically. The most common practice and way of diagnosing tuberculosis is by radiology and sputum examination, and both cannot confirm what type of tuberculosis bacterium is involved in the case. Despite this resurgence of $\mathrm{TB}$ in animals and man, and the consumption of large quantities of raw and sour milk in Zambia, no effort has been made to estimate the gravity of the risk and its threat to public health.

There has been no attempt towards isolation of Mycobacterium species from raw milk in Zambia. Therefore, this study was carried out to determine the prevalence of tuberculosis among traditional cattle used for milk production. Furthermore isolation of Mycobacterium species in the milk obtained from tuberculin positive cattle was carried out, with a view to highlight the risk of consuming raw milk.

\section{Materials and Methods}

Tuberculin test: During 2011-2012, a total of 1,025 cows aged between the range of $3-10$ years originating from Mapepe, Magoye, Monze, Batoka, GART- Batoka and Kalomo areas of southern Zambia, supplying major quantity of milk to processors originating from traditional cattle sector, were tested for bovine tuberculosis. For the determination of the prevalence of BTB in cattle, the single comparative intra-dermal tuberculin test (SCITT) was applied as per OIE [17]. Bovine and Avian tuberculin PPD containing 3000 IU/dose and $2500 \mathrm{IU} /$ dose respectively was obtained from Prionics Lelysatd B.V. Netherlands. Except Magoye dairy cooperative, all others, sell varying quantity of fresh raw and sour milk to the local community. Of the cows tested $72 \%$ were of local traditional breed and $28 \%$ constituted cross breds with $50 \%$ or less exotic dairy inheritance. Animal husbandry practices were free ranging. Budget constraint did not allow animals younger than the three years to be tested and also the male cattle were excluded in this TB testing programme. It is a legal requirement from the processors that farmers should supply milk only from TB and brucellosis negative cows.

Milk samples: $10 \mathrm{ml}$ of milk from 16 tuberculin positive cows was obtained from udder while milking, into sterile pre-cooled McCartney bottles after cleaning, washing and disinfecting the udder to avoid contamination from environment. Samples were taken to public health laboratory of The School of Veterinary Medicine at University of Zambia in a cooler box with ice and kept refrigerated at $4^{\circ} \mathrm{C}$ until analysis within 24 hours. Milk samples were centrifuged at 3,000 rpm for 15 minutes and the supernatant was discarded. The sediments were suspended in $2 \mathrm{ml}$ of sterilized physiological saline solution. To the suspension, equal volume of sterilized 4-N sodium hydroxide solutions and one drop of $0.05 \%$ phenol red indicator were added and the mixture was incubated for 30 minutes at $37^{\circ} \mathrm{C}$. Finally the samples were neutralized with sterilized 4$\mathrm{N}$ hydrochloric acid solution and centrifuged at 3,000 rpm for 15 minutes, and sediment was used for microscopic and cultural examination. Among 27 tuberculin positive cows, milk was obtained from only 16 cows that were in lactation, for milk smear examination and bacterial culture.

Pre-culture microscopic examination of the sediment: From sediments of each milk sample, two smears were prepared, dried, slightly fixed over flame and stained with Acid Fast Stain (Ziehl-Neelsen Stain). The stained smears were examined under oil-immersion lens of the microscope for demonstration of Acid Fast Bacilli (AFB) which stain as bright/rose red rods with a blue background.

Culture of the sediment and species differentiation: One $\mathrm{ml}$ aliquots of the sediments from each milk sample were spread on the surface of each of the LJ medium slants with glycerol and LJ medium slants with pyruvate. Cultures were incubated aerobically at $37^{\circ} \mathrm{C}$ for 8 weeks with weekly observation for signs of 
Table-1. Result of Tuberculin (SCITT) test

\begin{tabular}{|c|c|c|c|c|c|c|}
\hline Area of TB testing & $\begin{array}{l}\text { No. of cows } \\
\text { tested }\end{array}$ & $\begin{array}{l}\text { No. of TB } \\
\text { reactors }\end{array}$ & $\begin{array}{c}\% \text { TB reactors } \\
\text { tested }\end{array}$ & $\begin{array}{l}\text { No. of TB Test } \\
\text { inconclusive }\end{array}$ & $\begin{array}{c}\text { No. of TB } \\
\text { Non-reactors }\end{array}$ & $\begin{array}{c}\% \mathrm{~TB} \\
\text { Non- reactors }\end{array}$ \\
\hline Mapepe & 178 & 4 & 2.2 & - & 174 & 97.7 \\
\hline Magoye & 344 & 5 & 1.4 & 4 & 335 & 97.3 \\
\hline Monze & 310 & 16 & 5.1 & 4 & 291 & 93.8 \\
\hline Batoka & 94 & - & 0.0 & - & 94 & 0.0 \\
\hline GART-Batoka & 47 & - & 0.0 & - & 47 & 0.0 \\
\hline Kalomo & 52 & 2 & 3.8 & 1 & 48 & 92.3 \\
\hline Total & 1,025 & 27 & 2.6 & 9 & 989 & 96.4 \\
\hline
\end{tabular}

Table-2. Results of milk smear staining and cultural characteristics showing growth of Mycobacterium spp.

\begin{tabular}{lcccccccc}
\hline Area of milk origin & $\begin{array}{c}\text { Cow milk } \\
\text { sample ID }\end{array}$ & $\begin{array}{c}\text { Pre- culture } \\
\text { smear AFB }\end{array}$ & $\begin{array}{c}\text { Growth on } \\
\text { LJ -P }\end{array}$ & $\begin{array}{c}\text { Growth on } \\
\text { LJ -G }\end{array}$ & $\begin{array}{c}\text { Post culture } \\
\text { smear AFB }\end{array}$ & $\begin{array}{c}\text { Nitrate } \\
\text { activity }\end{array}$ & $\begin{array}{c}\text { Niacine strip } \\
\text { test }\end{array}$ & $\begin{array}{c}\text { Possible } \\
\text { Identity }\end{array}$ \\
\hline Magoye & MG-2 & + & + & - & + & - & - & M. bovis \\
Monze & MN-2 & - & + & - & + & - & - & M. bovis \\
Monze & MN-4 & - & + & - & + & - & - & M. bovis \\
\hline
\end{tabular}

LJ $-P=$ LJ Media with Pyruvate, LJ -G = LJ Media with Glycerol, (+) positive, (-) Negative

growth. The produced bacterial growth in slants with pyruvate that showed small, moist, creamy to yellowish, smooth, flat colonies after 4 weeks of incubation, were presumed to be $M$. bovis positive [18]. These isolates were further subjected to biochemical tests for characterization and identification as described by Kent and Kubica [19]. Growth on LJpyruvate is suggestive of $M$. bovis while those on $\mathrm{LJ}$ with glycerol is suggestive of M. tuberculosis, although there was no any growth on LJ-G slants. Positive controls with LJ-glycerol and LJ-pyruvate with known inoculated strain of $\mathrm{H} 37 \mathrm{Rv}$ and negative controls on LJ-glycerol and LJ pyruvate media without inoculation were also maintained for comparison. Confirmation and species differentiation of the Mycobacterium spp. isolates was done using the loop-mediated isothermal amplification system (LAMP) and multiplex-polymerase chain reaction (PCR) respectively according to Hang'ombe et al [20] on cultures showing growth. Briefly, the genomic DNA from Mycobacterium bacterial cultures was prepared from colonies using DNAzol reagent (Invitrogen, Carlsbad, CA, USA). A loopful of colonies was suspended in DNAzol followed by mechanical disruption as described by Suzuki et al [21]. The DNA was extracted according to the manufacturer's instructions and then dissolved in $50 \mu \mathrm{L}$ TE buffer (10 mM Tris/HCL (pH 8.0) and $1 \mathrm{mM}$ EDTA).The extracted DNA was then subjected to the LAMP test and multiplex-PCR as described earlier by Hang'ombe et al [20].

\section{Results}

A total of 27 (2.6\%) of the 1,025 cows tested were found tuberculin reactors, 9 of them $(0.87 \%)$ gave inconclusive reaction and $989(96.4 \%)$ were nonreactors (Table-1). Monze had the highest $5.1 \%$ followed by Kalomo (3.8\%), Mapepe (2.2\%), Magoye $(1.4 \%)$ TB reactos. Batoka and GART - Batoka did not record any $\mathrm{TB}$ reactor. Out of the 16 milk samples obtained from tuberculin positive cows and cultured, one of them (MG-2) showed acid fast bacilli on preculture sediment smear, while 15 did not show any acid fast bacilli. Of all the 16 milk samples sediment inoculated on LJ-P and LJ-G media, only 3 (18.7\% ) showed growth on LJ-P media (one on $6^{\text {th }}$ week of culturing and two on $7^{\text {th }}$ week of culturing) (Figure-1). This growth also included the sample that was positive for AFB (sample MG-2) on pre culture sediment. The number of colonies on the LJ-P media varied from 1-3. All three post culture smears were positive for AFB. LJ slants containing glycerol did not show any growth at the end of $8^{\text {th }}$ week of culturing. All the 3 isolates were Nitrate reduction negative and Niacine paper strip test production negative suggesting that isolates were most probably M. bovis (Table-2).

Only $1 / 16(6.2 \%)$ of the tuberculin test positive milk samples demonstrated AFB in the milk sample while $3 / 16(18.7 \%)$ of the tuberculin test positive milk samples cultured, showed growth of $M$. bovis. Thirteen milk samples $(81.2 \%)$ from tuberculin positive cows did not show any growth suggesting that these were probably not shedding TB bacteria in their milk.

To confirm the Mycobacterium grouping of the isolates, the LAMP system was used for rapid detection of the Mycobacterium tuberculosis complex (MTC) group.In this study, all the 3 cultures were confirmed as belonging to the MTC group (Figure-2). On further analysis using the multiplex polymerase chain reaction (PCR) for Mycobacterium species differentiation, the isolates were identified as Mycobacterium bovis following the amplification of a $786 \mathrm{bp}$ DNA fragment of the $c f p 32$ region (Figure-3).

\section{Discussion}

Our estimated overall prevalence of bovine tuberculosis in the study area (southern Zambia) was $2.6 \%$ which is lower than those reported by Munyeme et al [2], Cook et al [12], Muma et al [14], and Sitima et al [15] from Zambia and closer to those reported in Malawi [22], Tanzania [23] and Uganda [24]. The reason for lower prevalence rate than those previously reported in Zambia could be due to annual TB testing programme in place in our study area of southern Zambia and elimination of reactors from milk supply chain as legally required. Monze had the highest prevalence rate $(5.1 \%)$ followed by Kalomo (3.8\%), 


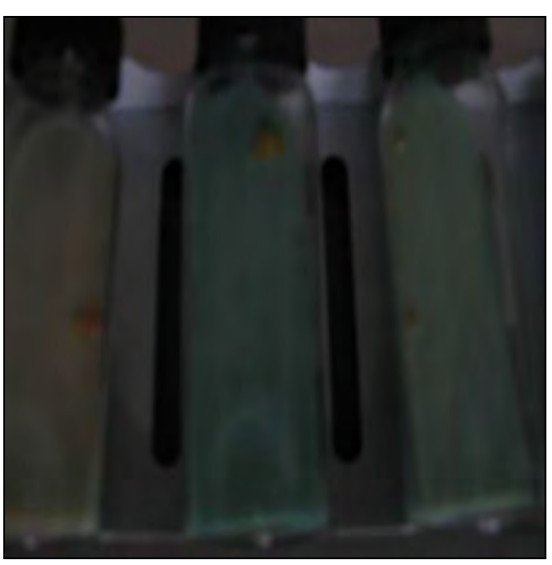

Figure-1. Growth of yellowish to creamish Mycobacterium spp colony on LJ -P media

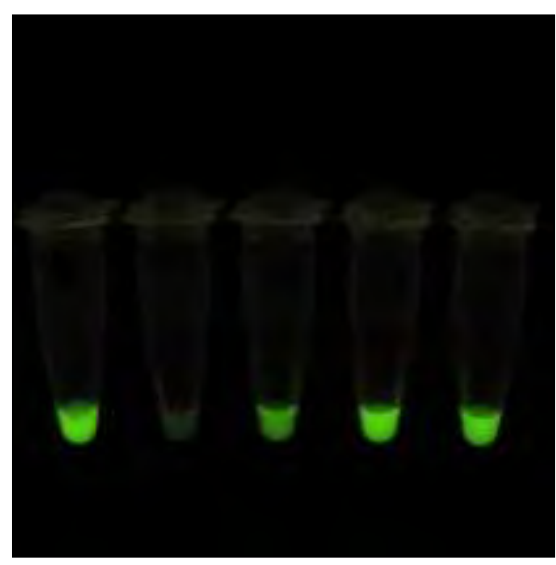

Figure-2. LAMP product observation under the UV light. Left to Right: Tube 1 and 2 are positive and negative controls respectively, while tubes 3, 4 and 5 are the Mycobacterium bovis isolates from raw milk.

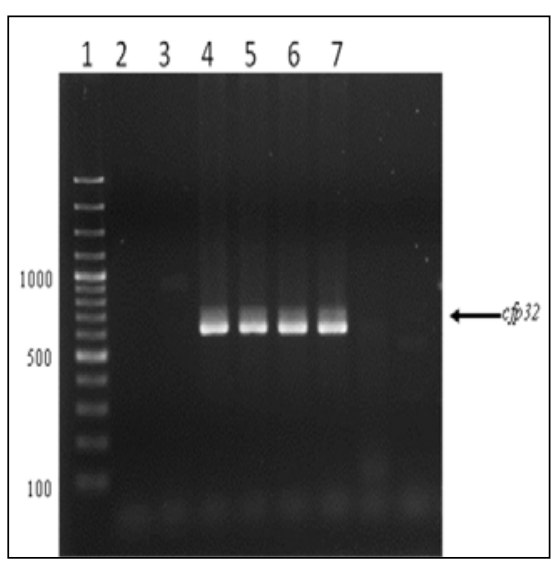

Figure-3. Agarose gel image showing multiplex-PCR amplification of a 786 bp fragment of the Mycobacterium bovis cfp32 region. Lane 1, 100 bp ladder; lanes $2 \& 3$ are negative controls, lane 4 is a positive control, lanes 5, $6 \& 7$ are Mycobacterium isolates from milk.
Mapepe (2.2\%), Magoye (1.4 \%) and Batoka and GART- Batoka did not record any TB reactor. Regular testing and elimination of TB reactors, from herds supplying milk for public consumption should be a regular practice supported by government and processors.

We report for the first time isolation of $M$. bovis from freshly drawn milk from 3 tuberculin reactor cows from Zambia based on cultural, biochemical and molecular tests. The definitive identification of the species of M. bovis is largely based on biochemical and molecular criteria which targets three genetic regions that are specific to species belonging to the MTC [25, 26]. Similar reports of isolation of M. bovis from milk of cows has been published from elsewhere in Nigeria [27], Turkey [28], India [29], Tanzania [30], Tunisia [31], Iraq [32] and Brazil [33, 34].

Our study, for the first time confirms the presence of zoonotic $M$. bovis in the milk of tuberculin reactor cows in Zambia. This further suggests that the three TB reactor cows, in our study were shedding viable $M$. bovis bacteria in their milk. The population consuming raw milk and HIV/AIDs affected individuals are at high risk of contracting the disease since the most common form of milk consumption is raw fresh and sour milk made from raw milk in rural areas of Zambia. Sitima et al [15] in an experimental study in Zambia reported the viability of $M$. bovis in traditionally made sour milk. Young children in rural areas and the babies born from HIV/AIDS positive mothers are encouraged to be given other forms of milk including cow's milk to avoid mother to child transmission of HIV/AIDS through breast feeding. Considering the report that $M$. bovis infection accounted for $1.6 \%$ of the cases of tuberculosis in HIV patients globally, the detection of this pathogen in cow's milk is worrisome as milk from cows forms the bulk of animal protein that is normally recommended for immune-compromised persons [11]. The presence of the zoonotic pathogen poses serious public health hazard to the herdsmen and other consumers of raw milk and milk products made from such milk [9]. It is common practice among herdsmen to depend upon the raw milk from cows as their main food while staying in the flood plains and many times they suckle milk directly from the udder of the cows.In countries like Zambia where milk is not usually boiled in rural areas before use, tuberculosis due to M. bovis may possibly be the major cause of extra pulmonary tuberculosis in humans. In this study $M$. bovis was detected in freshly drawn cow's milk from three TB reactors cows out of the $16 \mathrm{~TB}$ reactors and therefore the chances for human infection are high since cow's milk is regarded as one of the important foods in native population of Zambia. In addition, people living in Africa are comparatively at high risk due to close contact with animals and high incidence of HIV/AIDS [35].

From the study, it is quite clear that out of the six study areas in Zambia, Monze has higher prevalence rate of tuberculosis among cattle (5.1\%) (Table-1) and culture positive cases were two $(33.4 \%)$ out of the total culture positive cases of three $(66.6 \%)$ from Monze only. Cook et al [12] reported prevalence of positive reactors among cattle as $7.4 \%$ from a study in Monze alone. A good number of cattle population from Monze $30-45 \%$ move to Kafue flats for 6 months during dry season (June-November) in search of water and grazing and in the process mingle with Kafue lechwe (Kobus leche kafuensis) an antelope with concentrated population of about 40,000 at one place in Lochinvar Nantional Park [1]. These Kafue lechwe (Kobus leche kafuensis) had tuberculosis prevalence based on autopsy examination demonstrating TB resembling lesions as high as $24.0 \%$ [1] and $24.3 \%$ [36]. This could be one of the possible reasons for comparatively high prevalence and isolation rate of $M$. bovis among cattle originating from Monze area in our study as compared to other places studied.

The study also shows that bovine tuberculosis is animal and human health risk in the traditional dairy herds supplying milk to the Zambian population, 
especially in the informal market and needs attention of the public health and veterinary authorities. This study emphasized on the risk of transmission of TB to human via direct contact or ingestion of contaminated unpasteurized milk and milk products.

There is therefore a need for increased public health education to raise awareness on the consequences of consuming potentially TB bacteria contaminated, unboiled or unpasteurized milk, especially for those who are immune-compromised. Regular annual TB testing of all cattle and reactor's elimination from milk and beef supply chain should be supported by government through provision of farmer's compensation and budget allocation to veterinary department for annual tuberculin testing. Those who have no access to pasteurized milk should be educated through media and public health awareness campaigns to boil the raw milk before a consumer consumes or makes any other milk products.

\section{Conclusion}

The isolation of $M$. bovis in freshly drawn milk from the tuberculin positive reactor cows is being reported for the first time in Zambia. The study emphasizes the risk of transmission of $\mathrm{TB}$ to human through consumption of contaminated unpasteurized milk and milk products. There is a need for enhanced public health education to raise awareness on the consequences of consuming potentially contaminated milk. Also, measures need to be adopted to test and eliminate positive reactor cows from the dairy supply chain.

\section{Authors' contributions}

GSP initiated the research, carried out the milk sample collection, microbiological work and preparation of manuscript, FM and AK helped in tuberculin testing and interpretation of results, BMH carried out molecular confirmation of the bacterial isolates.

\section{Acknowledgments}

The authors are grateful to Dr. S. W. Muliokela, Director, Golden Valley Agricultural Research Trust, Lusaka, Zambia for financing tuberculin test in cattle through funds from Common Fund for Commodities and Ms. Chilambwe Mwila of Chest Diseases Laboratory of Ministry of Health, Lusaka, Zambia for technical support.

\section{Competing interests}

The authors declare that they have no competing interests.

\section{References}

1. Pandey, G. S. (1998) Studies on Infectious Diseases of Kafue lechwe (Kobus leche kafuensis) with particular reference to tuberculosis in Zambia. PhD Thesis, Azabu University, Japan.

2. Munyeme, M., Muma, J. B., Samui, K. L., Skjerve, E., Nambota, A. M., Phiri, I. J. K., Rigouts, L. and Tryland, M. (2009) Prevalence of bovine tuberculosis and animal level risk factors for indigenous cattle under different grazing strategies in the livestock/wildlife interface areas of Zambia. Tropical Animal Health and Production 41:345-352.
3. Sharma, R. N., Francis, B. K. T., Pandey, G. S. and Chizyuka, H. G. B. (1985) Goat Tuberculosis in Zambia. Indian J. Vet. Pathology 9:29-32.

4. WHO (2006) The control of neglected zoonotic diseases a route to poverty alleviation. Report of a joint WHO/DFIDAHP Meeting with participation of FAO and OIE, Geneva, Switzerland.

5. Ameni, G. and Erkihum, A.(2007) Bovine tuberculosis on small scale dairy farms in Adama Town, Central Ethiopia and farmers awareness of the disease. Revue Scientifique Technique Office International des Epizooties 26: 711-719.

6. Dankner, W. M., Waecker, N. J., Essey, E. M., Moser, K., Thompson, M. and Davies, C. E. (1993) Mycobacterium bovis infection in San Diego: a clinic - epidemiological study of 73 patients and historical review of a forgotten pathogen. Medicine (Baltimore) 72: 11-37.

7. Boland, F., Kelly, G. E., Good, M. and More, S. J. (2010) Bovine tuberculosis and milk production in infected dairy herds in Ireland. Prev. Vet. Med. 93:153-161.

8. Cosivi, O., Grange, J. M., Daborn, C. J., Raviglione, M. C., Fujikura, T., Cousins, D., Robinson, R. A., Huchzermeyer, H. F., deKantor, I. and Meslin, F. X. (1998) Zoonotic tuberculosis due to $M$. bovis in developing countries. Emerging Infectious Diseases 4, 59-70.

9. Ayele, W. Y., Neill, S. D., Zinsstag, J., Weiss, M.G. and Pavlik, I. (2004) Bovine tuberculosis an old disease but new threat to Africa. Review article. Int. Journal of Tuberculosis and Lung Diseases 8: 924-927.

10. Mwachalimba, K. K., Mumba, C. and Munyeme, M.(2013) Cost benefit analysis of tuberculosis control in wildlifelivestock interface areas of Southern Zambia. Prev. Vet. Medicine 110(2):274-279.

11. Kazwala, R. R., Daborn, C. J., Sharp, J. M., Kambarage, D. M., Jiwa, S. F. H. and Mbembali, N. A. (2001) Isolation of Mycobacterium bovis from human cases of cervical adenitis in Tanzania. A case of concern? Int. J. Tuberculosis and Lung Diseases. 9(1): 87-97.

12. Cook, A.J.C., Tuchili, L. M., Buve, A. Foster, S. D., GodfreyFausset, P., Pandey, G. S., McAdam, K. P. (1996) Human and bovine tuberculosis in the Monze district of Zambia- A cross-sectional study. British Veterinary Journal 152, 37-46.

13. ACF (2012) Performance and Competitiveness of the dairy value chain in Zambia. 1 (2): 1-4.

14. Malama, S. Muma, J. B. and Godfroid, J. (2013) A Review of Tuberculosis at the wildlife-livestock-human interface in Zambia. Infectious Diseases of Poverty. 2, 13-18.

15. Sitima, A. M. C., Pandey, G. S., Fujikura, T. (1997) Viability of $M$. bovis in traditionally sour milk and prevalence of bovine tuberculosis in Namwala district of Zambia. International Science Symposium, 9-11 ${ }^{\text {th }}$ April, Lusaka, Zambia.

16. Muma, J. B., Syakalima, M., Munyeme, M., Zulu, V. C., Simuunza, M., Kurata, M. (2013) Bovine Tuberculosis and Brucellosis in Traditionally Managed Livestock in Selected Districts of Southern Province of Zambia. Veterinary Medicine International, Article ID 730367, 7 pages http:/ /dx.doi.org/10.1155/2013/730367.

17. OIE (2010) Manual of the diagnostic Tests and Vaccines for Terrestrial Animals Vol 1. Office Int. Des. Epizootics, Paris, France.

18. Ofukwu, R. A., Oboegbulem, S. I., and Akwuobu, C. A. (2008) Zoonotic Mycobacterium species in fresh cow milk and fresh skimmed, unpasteurized market milk (nono) in Makurdi, Nigeria. Implications for public health. Journal of Animal and Plant Sciences 1 (1), 21-25.

19. Kent, T. P. and Kubica, G. P. (1985) Public Health Mycobacteriology. A guide for level III laboratory. United States Human Health Services, Centre for Disease Control, Atlanta, Georgia 30, 333-350.

20. Hang'ombe B., Nakajima C., Ishii A., Fukushima Y., Munyeme M., Matandiko W., Mweene A. S., Suzuki Y. (2011) Rapid detection of Mycobacterium tuberculosis 
complex in cattle and lechwe (Kobus leche kafuensis) at the slaughter house. Veterinary Science Development. 1:e5.2426.

21. Suzuki Y., Katsukawa C., Inoue K., Yin Y., Tasaka H., Ueba N., Makino M. (1995) Mutations in rpoB gene of rifampicin resistant clinical isolates of Mycobacterium tuberculosis in Japan. Kansenshogaku Zasshi. 69:413-419.

22. Bedard, B. G., Martin, S. W. Chinombo, D. (1993) A prevalence study of bovine tuberculosis and brucellosis in Malawi. Preventive Veterinary Medicine 16 :(3), 193-205.

23. Shirima, G. M., Kazwala, R. R. and Kambarage, D. M. (2003) Prevalence of bovine tuberculosis in cattle in different farming systems in the eastern zone of Tanzania. Preventive Veterinary Medicine 57 (3): 167-172.

24. Oloya, J., Opuda- Asibo, J. and Djonne, B. (2006) Responses to tuberculin among Zebu cattle in the transhumance regions of Karamoja and Nakasongola district of Uganda. Tropical Animal Health and Production 41 (4): 275- 283.

25. Fentahun, T. and Luke, G. (2012) Diagnostic Techniques of Bovine Tuberculosis. A Review. African Journal of Basic and Applied Sciences 4 (6): 192-199.

26. Nakajima C., Rahim Z., Fukushima Y., Sugawara I., van der Zanden A. G., Tamaru A. and Suzuki Y. (2010) Identification of Mycobacterium tuberculosis clinical isolates in Bangladesh by a species distinguishable multiplex PCR. BMC Infect Dis.10:118 - 122 .

27. Simeon, I. B.C., Mohamad, K.Y., Abdullahi, A. M., Akinbowale, O. J. and Dick van Soolingen (2010) M. bovis and $M$. africanum present in raw milk of pastoral cattle in North Central Nigeria. Tropical Animal Health and Production 42 (6): 1047-48.

28. Aydin, F. E., Ulger, M., Emekdas, G., Asian, G. and Gunal, S. (2012) Isolation and identification of $M$. bovis and nontuberclous mycobacterium in raw milk samples in Mersin province of Turkey. Mikrobiyol Bull 46 (2), 283-289.
29. Srivastava, K., Chauhan, D. S., Gupta, P., Singh, H. B., Sharma, B. D., Yadav, V. S., Thakral, S. S., Dharamdheeran, J. S., Prasad, H. K. and Katoch, V. M.(2008) Isolation of M. bovis and M. tuberculosis from cattle of some farms in North India- Possible relevance in human health. Indian Journal of Medical Research 128(1), 26-31.

30. Kazwala, R. R., Daborn, C. J. and Kushiluka, C. J. M. (1998) Isolation of Mycobacterium spp from raw milk of pastoral cattle of Southern Highlands of Tanzania. Trop. Anim. Hlth. Prod. 30, 233-239.

31. Kahla, I. B., Boschirdi, M. L., Souissi, N. C., Cherif, N., Benzarti, M., Boukadida, J. and Hammami, S. (2011) Isolation and molecular characterization of $M$. bovis from raw milk in Tunisia. Afr. Health Science, August 11 (S1): S2-S5 PMCID:PMC 3220130.

32. Al- Saqur, I. M., Al-Thwani, and Al-Attar I. M. (2009) Detection of Mycobacteria spp in cows milk using conventional methods and PCR. Iraqi Journal of Vet. Sciences23: 259- 262.

33. Pardo, R. B., Langoni, H., Mendonca, L. J. P. and Chi, K. D. (2001) Isolation of Mycobacterium spp from cows suspected or positive to tuberculosis. Braz. J. Vet. Res. Anim. Sci.http://dx.doi.org/10.1590/S1413-95962001000600007.

34. Franco, M. M. J., Paes, A. C., Ribeiro, M. G., Pantoja,J. C.F., Santos,A. C. B., Miyata, M., Leite, C. Q. F., Motta, R. G. and Listoni,F. J. P. (2013) Occurrence of Mycobacteria in bovine milk samples from both individual and collective bulk tanks at farms and informal markets in the southeast region of Sao Paulo, Brazil. BMC Vet Res. 9: 85.

35. WHO (2009) Global Tuberculosis Control: Epidemiology, Strategy, Financing, WHO Report 2009, WHO/HTM /TB2009. 411: 1-309.

36. Munyeme, M., Muma, J. B., Siamudaala, V. M., Skjerve, E., Munangandu, H.M. and Tryland, M. (2010) Tuberculosis in Kafue lechwe (Kobus leche kafuensis) of the Kafue Basin in Zambia. Preventive Veterinary Medicine 95: 305-308. 